\title{
El Salvador: la democracia entre la guerra y la posguerra
}

Raúl Benítez Manaut

CIIH/UNAM

$\mathbf{E}$

n el presente ensayo presentamos un breve repaso histórico la interrelación existente entre la oligarquía (terrateniente-cafetalera) y el aparato militar, como la instancia estatal responsable de garantizar la estabilidad del conjunto, de la vida social. Posteriormente, se analizan los aspectos más relevantes de la discusión ideológica y política en el periodo de la guerra civil (1979 en adelante), para finalmente mencionar el debate actual (circunscrito a la polémica sobre la consolidación de las estructuras legales que garantizan formalmente un proceso democrático) y que, sin la participación del conjunto de las fuerzas políticas del país, es incompleto. Principalmente el nudo gordiano reside en la participación del FMLN una vez desarmado y transformado en fuerza política (o fuerzas políticas).

El tema de la democracia política y la democracia social en El Salvador es sin duda uno de los ejes cardinales del actual conflicto que vive ese país. El hecho que determinó el conjunto de los acontecimientos en la sociedad salvadoreña hasta enero de 1992, la guerra civil, estalló porque ni la democracia social ni la política se dieron en sus mínimas expresiones. Así, a diferencia de otros países de América Latina, la demanda de democracia -social y política- no pudo canalizarse 


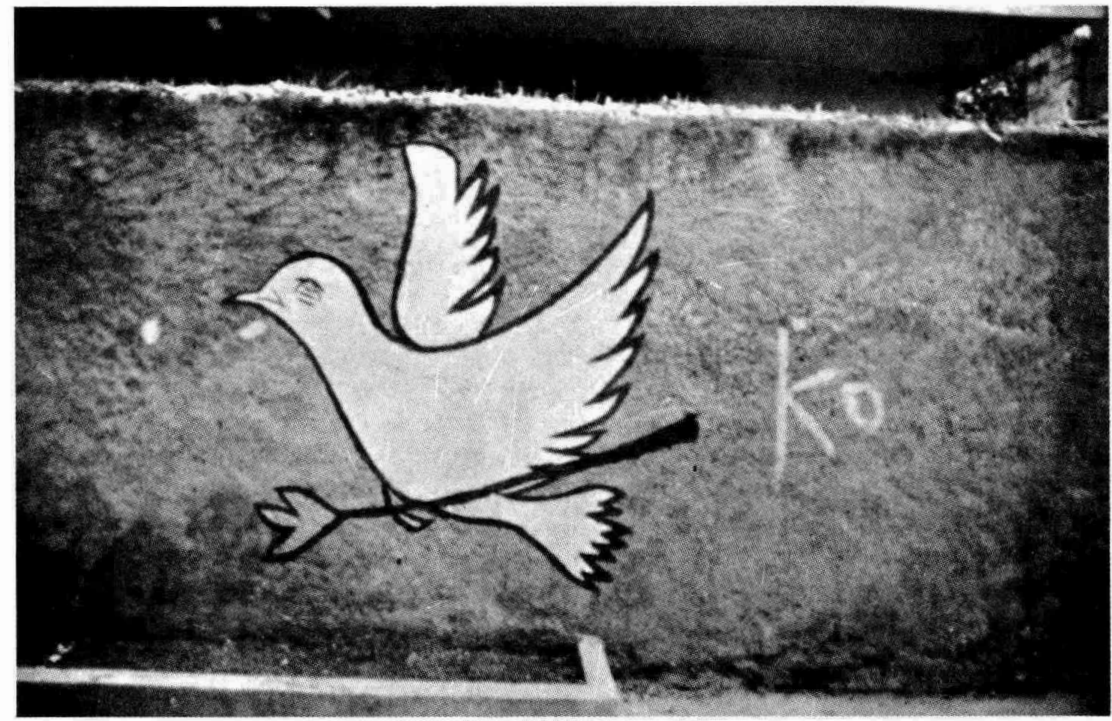

por otros medios que no fueran los violentos.

En El Salvador, cuando el conflicto social adquirió dimensiones superiores en 1979, son claras las diferencias en cuanto a las posibles alternativas para el país. Al darse el golpe de Estado de octubre de 1979, la proclama de la fuerza armada ${ }^{1}$ menciona de forma explícita la necesidad de hacer profundas reformas estructurales para darle salida a la grave situación política. En ese momento incluso los planteamientos de democracia social provinieron del seno de las fuerzas armadas. Durante 1980 , los proyectos sociopolíticos en pugna se decantan al no darse

1 "Proclama", en Castro Morán, Funcion, 1984 , pp. 412-415. una solución negociada al conflicto. Uno de los vértices de este enfrentamiento se da en el plano ideológico, expresando las fuerzas políticas existentes concepciones diferentes e incluso antagónicas de democracia.

En el momento de estallar la guerra civil en enero de 1981, la pugna pasa al nivel militar y las concepciones de democracia se diversifican. La profundización de la guerra civil en la década de 1980 es la limitación más importante para que la lucha por la democracia se dirima por métodos democráticos, entendiendo estos métodos como la necesaria premisa de la paz, y sus dos condicionantes ineludibles en países con las características de El Salvador: democracia política y desarrollo económico que garanticen 
una distribución equitativa mínima de la riqueza para que en el seno de la sociedad no persistan los gérmenes de la confrontación violenta.

\section{OLIGARQUÍA Y MILITARES}

Históricamente, la democracia es una palabra ajena a la vida política de El Salvador. Desde su nacimiento como nación, la conformación de grupos sociales basados en lo que la sociología ubica como de una sociedad tradicional, predomina sobre las formas que adquiere en otras regiones la modernidad. En el nivel social, la rígida estratificación existente, marcada por la presencia determinante de 14 familias poseedoras de las mejores tierras, muestra la existencia de esta poderosa oligarquía cafetalera que, aunque algo diversificada en la actualidad, no ha transformado de forma radical sus bases de sustentación económica y política. ${ }^{2}$ La modernización observada en la economía desde mediados del siglo XX no se expresa en el nivel político. Éste es un factor que se observa en toda Centroamérica, con la honrosa excepción de Costa Rica.

El primer elemento que salta a la vista es que, a diferencia de México o de muchos países de América del Sur, la crisis de la dominación oligárquica, que en El Salvador fue golpeada con singular fuerza por ser, en el momento del estallido de la crisis del 29 , un país eminentemente cafetalero, no trajo consigo la modernización del Estado, la mayor participación de las

2 Colindres, Fundamentos, 1977. masas en el escenario sociopolítico o la modernizacion de la economía. Su efecto se tradujo en la transformación del poder político, apareciendo y consolidándose el militarismo. ${ }^{3}$ Una expresión de rebeldía campesina a principios de 1932 fue disuelta de forma singularmente sangrienta -con la muerte de aproximadamente $30 \mathrm{mil}$ campesinos-, apuntalándose el gobierno del general Maximiliano Hernández Martínez. ${ }^{4}$ Esto hace que El Salvador sea un pais donde, tradicicnalmente, la lucha política se regula en forma militarizada, siendo por ello las fuerzas armadas un factor políticu de primer orden. Un estudio sistemático sobre el papel político del ejército menciona:

En este siglo $\mathrm{xx}$, el ejército ha realizado hasta el momento siete golpes de Estado triunfantes y dos fracasados. [...] En algunas ocasiones, el ejército ha prestado oídos a los clamores del pueblo. En otras circunstancias ba defendido denodadamente los intereses de la oligarquía. Algunas veces ha organizado partidos políticos, otras se ha plegado a la influencia de ellos. En ciertas oportunidades ha prestado atención al clero en alianza con la oligarquía, y en otras, ha sintonizado las vibraciones del clero progresista. En algún caso, con el general Hernández Martínez, por ejemplo, ha sido acérrimamente nacionalista. En la actualidad, es sensible a las presiones internacionales. 5

Esta forma tradicional de ejercer el

3 Guidos Béjar, Ascentso, 1980.

- Anderson, Matanza, 1981.

5 Castro Morán, Función, 1984, p. 26. 
poder político de modo directo pór parte de las fuerzas armadas es el factor determinante para que la democracia política y social no pueda lograrse de las maneras que se establecen en el pensamiento político liberal: los métodos políticos basados en las elecciones y lo que ello supone: su realización bajo reglas de juego igualitarias y no excluyentes $y$, finalmente, el respeto de los gobernantes a los sufragios. Por ello, en El Salvador la militarización e ideologización de la política desembocó en la guerra civil. Esto a pesar de que, como resultado de la revolución de 1948 , se buscara la legitimación del bloque en el poder a través de métodos electorales.

Sin embargo, ello no quiere decir que los actores políticos del pais, representantes de los diferentes sectores sociales, no hayan planteado la necesidad de efectuar reformas; tanto a la estructura política como a la organización social y a las estructuras económicas. Por eso, uno de los vértices de la lucha por la de. mocracia se concentra en la dualidad civilismo-militarismo. Una peculiaridad del caso salvadoreño es que los primeros cuestionamientos al orden tradicional provinieron de los sectores populares agrupados en gremios y no en partidos políticos. ${ }^{6}$ En 1930 se funda el Partido Comunista de El Salvador, siendo la primera agrupación definida explícitamente para representar a los sectores populares. Este partido fue casi destrozado por la represión de 1932 en sus inicios, logrando sobrevivir en la clandestinidad.

\footnotetext{
${ }^{6}$ Menjivar, Formación, 1982.
}

Ello debido a las pugnas que en esa época caracterizaban a los modelos existentes, identificándose al gobernante dictador, Hernández Martínez, con el fascismo. Así, la política en El Salvador pasa de una dominación oligárquica a una dictadura personalista. En el contexto de formas de gobierno militares-personales, la expresión política de la oposición se oculta, lo que da pie a la descomposición del dictador en los años 40, por presiones externas y por movimientos conspirativos. Hacia 1948, con la llamada "Revolución del 48", zan a configurarse los primeros gérme. nes de un sistema político moderno, pasando de la dominación militar unipersonal a un militarismo institucional. En este contexto los militares ven la necesidad de recurrir a la oligarquía para poder consolidar su dominación, y se estructura un sistema de partidos políticos, pero siempre buscando la elite militar la conformación de un partido oficial o dominante. ${ }^{8}$ Así, en 1950 se funda el Partido Revolucionario de Unificación Democrática (PRUD) -que vivió hasta 1960- y su sucesor, el Partido de Conciliación Nacional (PCN), en 1961.9 La característica del periodo inaugurado tras la revolución del $\mathbf{4 8}$ fue un nuevo sistema de dominación militar-oligárquico que se mantiene inalterado hasta el golpe de Estado del 15 de octubre de 1979.

En este periodo (1948-1979) aparecen la mayoría de las fuerzas políticas que actualmente tienen una pre-

${ }^{7}$ Cáceres, El Salvador, 1988.

a Baloyra, El Saluador, 1987, cap. 3: "Los partidos y la política en El Salvador", pp. 55.77.

9 Ibid., p. 57. 
sencia activa en el acontecer del país. En los años sesenta son fundados el Partido Demócrata Cristiano (PDC), en 1960, y el Movimiento Nacional Revolucionario (MNR), en 1965, el primero inspirado en el pensamiento socialcristiano, que en ese entonces cobraba creciente influencia en la gran mayoria de los países latinoamericanos, y el segundo, en una explícita definición ideológica socialdemócrata. Ambos partidos son encabezados, prácticamente desde su origen, por "caudillos" políticos: el PDC por José Napoleón Duarte y el MNR por Guillermo Ungo. Esta mención del liderazgo político es muy importante porque estas fuerzas políticas son las que, en los años sesenta y principios de los setenta, expresan nuevas concepciones de "democracia", basadas en la necesidad de modernización y democratización de las estructuras económicas y políticas del país: ambas se suman a los planteamientos de realización de una reforma agraria (que afectaría notablemente a la oligarquía) y a la democratización del sistema político, y ambos partidos postulan y reconocen a la organización política liberal como la forma idónea de participación política.

En ese entonces el planteamiento de democracia social y democracia política cobra fuerza y es el puntal sobre el que se organiza la Unión $\mathrm{Na}$ cional Opositora (UNO) para las elecciones de $1972 .{ }^{10}$ Los principales te-

10 La UNo está integrada por el PDC, el MNR y la Unión Democrática Nacionalista (UDN), conocida como Frente Electoral del Partido Comunista. Se presentaron como candidatos a la presidencia y vicepresidencia Duarte y Ungo, respectivamente. mas de campaña de la unO fueron la realización de una profunda reforma agraria y la restauración de las libertades democráticas. En sus discursos los candidatos denunciaron al imperialismo, a la oligarquía y a los militares como aliados, para evitar que con fórmulas nuevas llegaran éstos a tomar el poder en El Salvador. El resultado oficial de dichas elecciones fue 314000 votos para el PCN versus 292000 para la UNo. ${ }^{11}$ La gran mayoría de los observadores sostienen que se cometió un gran fraude electoral en contra de la UNO. Esto hizo que numerosos sectores políticos hablaran de la imposibilidad de acceder al poder por medios legales y a través de las elecciones, apareciendo así las organizaciones que sostienen la lucha armada como única opción. Esta situación se repitió en las elec. ciones presidenciales de 1977, con la postulación de un candidato de la UNO -Ernesto Claramount- que fue impedido de acceder al poder por el fraude electoral organizado por el PCN.

Los setenta son los años en que la situación social y política se presenta favorable para el estallido de la gue. rra civil. En lo social, las consecuencias de la guerra de 1969 con Honduras ${ }^{12}$ afectan en primer lugar a una masa de campesinos desposeídos que fueron deportados de ese país y que demandaron con insistencia tierras para poder subsistir. La mayoría de estas personas se ubicaron en la periferia de las ciudades y fueron el germen del movimiento radical de protesta campe-

11 Gordon, Crisis, 1989, p. 134.

12 Jiménez, Guerra, 1974. 
sina, generalizándose la protesta popular en el sector agrario. ${ }^{13}$ En lo político, hay una resistencia de la elite militar y oligárquica a aceptar la participación de los sectores emergentes (PDC y MNR básicamente), además de a la gran cantidad de organizaciones sociales, estudiantiles, campesinas, religiosas, gremiales, etcétera que surgen, por lo que se generaliza la violencia social y política en todo el país. De esta manera, se va gestando un ambiente de polarización favorable para que la situación se defina únicamente a través de las armas. Por ello, crecientemente cobra importancia la acción de las llamadas "organizaciones político-militares" y la defensa de las fuerzas armadas y cuerpos de seguridad en lo que respecta al mantenimiento del statu quo.

\section{El ASCENSO DE LA DEMOCRACIA POPUIAR-REVOLUCIONARIA}

Las organizaciones político-militares surgen con el principio de que el cambio político y social no es posible en circunstancias de legalidad, rechazando las posibilidades de "democracia política". La primera de ellas se crea en 1970: las Fuerzas Populares de Liberación Farabundo Martí (FPL); la segunda, en 1972; el Ejército Revolucionario del Pueblo (ERP); la tercera, en 1975: la Resistencia Nacional (RN); la cuartal en 1976: el Partido Revolucionario de los Trabajadores Centroamericanos (PRTC) y la quinta es la con-

13 Cabarrús, Génesis, 1983; Celarié, Surgimiento, 1983. versión y aceptación de la lucha armada por el PCS, en 1979, al crear las Fuerzas Armadas de Liberación (FAL). ${ }^{14}$ Estas cinco organizaciones, que tienen una identificación ideológica con el marxismo-leninismo, rechazan en ese momento la posibilidad de que sus acciones puedan conducir a una democracia política, aduciendo el hecho de que la "democracia social" es prioritaria y sólo se puede lograr ésta por la vía de la toma del poder -hacia 1979 el ejemplo de Nicaragua es determinante sobre el diseño de las estrategias de las cinco organizaciones. En términos ideológicos y políticos enfrentan sus concepciones con las de aquellos que quieren buscar cambios por la vía "reformista" (como la junta de gobierno instaurada con el golpe de Estado de octubre de 1979, el MNR y el PDC) y con las fuerzas de seguridad del Estado, que para entonces están escindidas como sigue: el sector de oficiales que apoyó el golpe de Estado, y que busca una salida pactada y reformista; el sector de oficiales de las fuerzas armadas que no apoyaron el golpe de Estado y que representan los intereses tradicionales oligárquicos; y los mandos de los cuerpos de seguridad, en ese entonces responsables directos de la represión indiscriminada, y siendo en parte un poder real en el seno de las estructuras estatales.

Las cinco organizaciones políticomilitares mencionadas desarrollan sus acciones de guerrilla en todo el territorio $y$, en 1980, logran ir agrupan-

14 Esto lo hemos analizado en dealle en, Benítez Manaut, Teorta, 1989, cap. "La guerra. Primer periodo, 1970-1980", pp. 211-252. 
do a gran cantidad de organizaciones sociales, campesinas, laborales, estudiantiles, religiosas y políticas, y crean un gran frente político que respalda el esfuerzo militar: el Frente Democrático Revolucionario (FDR).$^{15} \mathrm{La}$ creación del FDR se da cuando el "momento reformista" de la junta de gobierno constituida en octubre de 1979 habia terminado. De octubre a diciembre de 1979 se emiten tres decretos que afectan notablemente a la oligarquía: la reforma agraria, la nacionalización de la banca y la nacionalización del comercio exterior. Básicamente es perjudicado el sector exportador, encabezado por los grandes cafetaleros.

Desde los inicios de 1980 , el proyecto de hacer las reformas sociales (o la democracia social) "desde arriba" fracasa. El sector que impulsa las reformas se escinde por la acelerada polarización que se vive en el país. El PDC busca una alianza con el alto mando de las fuerzas armadas excluyendo a los miembros progresistas de la junta (militares y políticos, principalmente los dirigentes de la Universidad Centroaméricana-UCA-y el MNR). El PDC y el sector conservador del ejército son respaldados por Estados Unidos. Se firma así un pacto entre el PDC y la fuerza armada, encabezando la junta José Napoleón Duarte. ${ }^{16}$ Así, aparece un proyecto de "reformismo contrain-

15 El fDr se funda el 18 de abril de 1980 . Su antecedente es el Foro Popular, creado en agosto de 1979 y en el cual, en el momento del golpe de Estado de octubre de 1979, los militares se apoyaron políticamente.

16 "Pacto", en Castro Morán, Función, 1984, pp. 416-419. surgente" respaldado por Estados Unidos, $y$ un proyecto "popular revolucionario", agrupado en el FDR.

Una interpretación de lo sucedido en 1979-1980 se puede explicar de la siguiente manera: se pasa de lo que el italiano Antonio Gramsci entiende por "guerra de posiciones", es decir la conquista del Estado por la vía política (cuyo momento más importante en El Salvador fue el golpe de octubre de 1979), ${ }^{17}$ a lo que los teóricos de la guerra (Clausewitz) entienden por "guerra de posiciones": la toma del poder (por la vía militar) y la derrota del adversario. Para ello, 1980 es el año en que se decide, por ambas partes, "no negociar" y desplegar con todas sus consecuencias las estrategias militares correspondientes de toma del poder (la parte democrática y revolucionaria) y de defensa del poder (la oligarquía y las fuerzas armadas).

El sector popular-democrático-revolucionario se decanta y divide su acción en lo que es el "frente político" y el "frente militar". El primero, con la creación del FDR, y el segundo con la integración de las cinco organizaciones político-militares en una instancia de coordinación superior el $\mathbf{1 0}$ de octubre de 1980: el Frente Farabundo Martí para la Liberación Nacional (FMLN). La guerra civil estalló el 10 de enero de 1981.

17 Jiménez, El Salvador, 1988. 
DEMOCRACIA Y GUERRA CIVIL

(1981-1987)

Para la teoría política es un reto la interpretación de los fenómenos políticos en momentos en que un país se involucra en una guerra civil. De hecho, en esas circunstancias "la guerra determina la política" o es la "continuación de la política". Sin embargo, las fuerzas políticas que no tienen estrategia militar y fuerzas armadas, buscan no perder su personalidad e identidad política. En El Salvador eso sucedió con partidos políticos como el PDC, el MNR y el Movimiento Popular Social Cristiano (MPSC), una escisión del PDC que en 1980 se incorporó al FDR. El resto de los partidos políticos, principalmente los pertenecientes al "viejo sistema de partidos", perdieron influencia en forma acelerada -básicamente el PCN.

El PDC, integramente respaldado por Estados Unidos, buscó convertirse en una "tercera fuerza" que pretendía canalizar a su favor, tanto la necesidad -planteada básicamente por Estados Unidos- de "democracia política" como de "democracia social". Así, la figura de Duarte emergió como la cabeza de un proyecto no radical de reformismo. ${ }^{18}$ El PDC, entre $1980 \mathrm{y}$

18 Este aspecto es analizado en deralle en Córdova, "Periodización", 1988. El proyecto de reformas con contrainsurgencia es parte de una concepción integral de las teorías de la contrainsurgencia. Los mandos militares enviados por Estados Unidos a El Salvador, que en realidad sustituyeron al Estado Mayor de las fuerzas armadas en la planeación de las operaciones militares, hicieron mucho énfasis en la necesidad de las "reformas" sociales. Véanse Waghelstein, "El Salvador", 1984; Waghelstein y Bernstein, "How", 1985.
1982, encabezó la junta de gobierno, misma que se propuso dcs objetivos: contener la posibilidad de triunfo militar del FMLN y lograr reconstruir, de las cenizas, el poder político y las instituciones políticas, a través de la "democracia electoral". ${ }^{19}$ El sistema busca de forma urgente "mecanismos de legitimación" a través de las elecciones. Se realizan elecciones en marzo de $\mathbf{1 9 8 2}$ para constituir una asamblea constituyente, lográndose una nueva legalidad constitucional, misma que culmina en diciembre de 1983 con la aprobación de la nueva Constitución. ${ }^{20}$ La redacción de esta Constitución se realizó con base en un pacto entre el PDC, las fuerzas armadas y la representación política de la oligarquía (principalmente ARENA y PCN, conocido como Pacto de Apaneca y firmado el 3 de agosto de 1982.21

19 Incorporar la construcción de sistemas políticos democráticos en países que viven guerras civiles ha sido una de las formas en que Estados Unidos ha incorporado sus estrategias de contrainsurgencia. Algunos autores han llamado a esto "democracia de demostración" y pretenden demostrar que en dichos paises hay democracia política, por lo cual es "innecesario" que los "comunistas" continúen su esfuerzo de toma de poder por la vía de las armas. Véase Herman y Brodhead, Demostration, 1984. La necesidad de "democracias de demostración es para lograr que no aparezcan resistencias en el Congreso de Estados Unidos al esfuerzo militar de asistencia".

${ }^{20}$ Constitución polltica, 16 de diciembre de 1983.

21 El Pacto de Apaneca fue muy relevante debido a que se sustituye a las anteriores juntas de gobiemo por un gobierno de "Unidad Nacional" legítimamente constituido. Ademis, mostró las posibilidades del nuevo "bloque de poder", que literalmente significa una alianza para contener al FMLN en lo militar y evitar 
De esta manera, se conforma una realidad polarizada determinada por una guerra civil, donde los hechos políticos están subordinados a los militares y donde el desarrollo de los acontecimientos en el campo de batalla determina la vida política -que por lo demás, se militariza. Por ello, entre 1981 y 1987 , El Salvador vive en realidad una situación de polaridad político-militar, estando en un polo el sector conservador basado en una nueva alianza (Estados Unidos, fuerzas armadas, ARENA -representando a la oligarquía- y PDC -encabezando el proyecto de democratización y reformismo contrainsurgente); y en el polo democráticopopular-revolucionario, la alianza FDRFMLN, desagregándose la misma en el liderazgo socialdemócrata y socialcristiano del MNR y MPSC, por un lado, y por el otro, en un liderazgo militar formado por las cinco organizaciones que se agrupan en el FMLN. Tanto en la relación FDR y FMLN como en el seno

las posibilidades de que la alianza del FDR tenga posibilidades de participar políticamente con exito. Fue respaldado íntegramente por las fuerzas armadas y Estados Unidos. Este pacto mostro, además, las posibilidades de las alianzas entre el PDC y los proyectos de restauración oligárquica, basados en la creación de la Alianza Republicana Nacionalista (ARENA), fundada en septiembre de 1981 por Roberto D'Abuisson con el proposito explícito de evitar que se consolidara, en primer lugar, el proyecto "popular-revolucionario", y en segundo lugar, el "reformismo del PDC". Sin embargo, por la guerra civil, la participación creciente de Estados Unidos en el proceso de toma de decisiones en el interior de El Salvador, dada la dependencia de la asistencia de éste, hace que esta nueva derecha, u oligarquía restaurada, tenga que aceptar la alianza con el PDC. del FMLN, existen numerosas diferencias que van desde la interpretación de la reconstrucción del sistema político hasta las de estrategia militar.

En política, el esfuerzo de legitimación del nuevo bloque en el poder se da de manera integral. Los recursos económicos para esta empresa los provee fundamentalmente Estados Unidos. La Constitución de diciembre de 1983 y la "normalización" del proceso político a través de las elecciones (basadas en tres estructuras: presidenciales, para la Asamblea y municipales) logran la reconstitución del sistema político. ${ }^{22}$ Después de las elecciones de 1984 (cuando Duarte asume la presidencia en forma constitucional) muchos gobiernos reconocen al nuevo régimen salvadoreño, acontecimiento que en el seno de la alianza FDR-FMLN se observa con preocupación.

Entre 1981 y 1987 , el desarrollo de la guerra civil nulificó de forma importante los gérmenes de "democracia social" que se habían dado en la sociedad civil. La represión gubernamental en las ciudades contra líderes estudiantiles, sindicales y populares (considerados "la base social de la guerrilla") fue abierta, y las violaciones a los derechos humanos se manifestaron, quedando sólo espacio para un juego político de los partidos que van del "centro" (PDC) a la extrema dere. cha. Así, se vuelve a dar una corresponsabilidad entre lo militar (la estrategia denominada desde 1984 de "guerra de baja intensidad") ${ }^{23}$ y lo político. A este

22 Esto lo hemos analizado en Benítez Manaut, "El Salvador", 1990.

23 Bermúdez, Guerra, 1987. 
proceso de "democracias contrainsurgentes" se le ha denominado también de "democracias de baja intensidad".

El desarrollo de la guerra civil trasnacionaliza a El Salvador en todos los niveles. La economía, al transformarse en una economía de guerra, necesita para su mantenimiento de la creciente asistencia de Estados Unidos; y la población que habita en las zonas de guerra tiene en gran parte que abandonar sus lugares de origen, dándose grandes migraciones al occidente del país, a la periferia de las ciudades importantes (San Salvador y Santa Ana) y al extranjero, principalmente hacia Estados Unidos. La población campesina que persiste en sus poblados se convierte en la base social del FMLN, desarrollándose un "poder popular" en algunas regiones (San Vicente, Chalatenango y Morazán), con formas de vida política totalmente diferentes (a esta relación de liderazgo en sus zonas bajo control, la denomina el FMLN, "democracia popular"). También a nivel cultural, como consecuencia lógica de la guerra, se desarrolla rápidamente una militarización de la vida cotidiana, lo que es un obstáculo para las posibilidades de la democracia en todos sus niveles: social y política. La trasnacionalización de El Salvador en la década de los ochenta tiene un efecto positivo: es imposible un retorno al statu quo anterior al haberse hecho inviables las formas de dominación oligárquica y militarizada. Por ello, a pesar de que el nacimiento de la democracia se da en un contexto de mi-

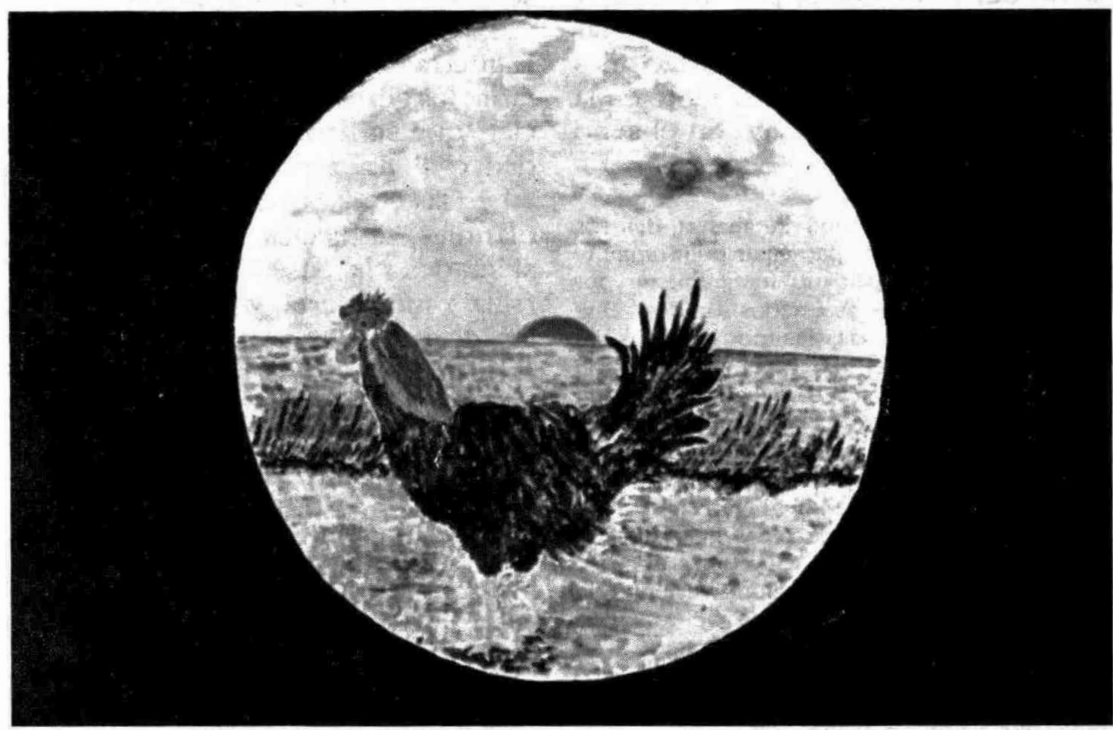


litarización y guerra civil, y de que es excluyente, se consolida en términos legales y reales, por lo que la maduración de la "democracia electoral" no puede ser minimizada.

\section{DEMOCRACIA, APERTURA POLÍTICA Y GUERRA CIVIL (1987-1991)}

Con la firma de los acuerdos de paz conocidos como Esquipulas II, el 7 de agosto de 1987 se abre un nuevo periodo en la historia de la crisis y de la guerra civil. La dinámica ascendente de la guerra, que implica un "empate técnico" sin posibilidad de victoria militar de ninguno de los dos ejércitos, posibilita la reaparición del nivel político, y la guerra regresa al dilema de 1980: negociación-paz y democracia versus guerra civil. La realidad salvadoreña ha sufrido una mutación nunca antes vista en su historia y, debido a ella, hay nuevos factores que comienzan a influir para que se abra la expectativa del fin de la guerra civil. El más importante de ellos es el cansancio de la guerra, que se manifiesta en todos los sectores sociales y políticos, sin distinción del grupo social al que pertenezcan o a su identificación política e ideológica.

En el seno del FDR, los partidos MNR y MPSC deciden regresar a efectuar vida política en el interior del país e incluso participar en las elecciones presidenciales de marzo de 1989. Para ello, de forma evidente se reformula la alianza FDR con el FMLN. Reaparece el dilema de Gramsci opuesto al de Clausewitz, pues se sostiene como posible el efectuar una "guerra de posiciones" en el nivel político, reconociendo de facto la legalidad existente. La nueva posición del MNR y MPSC se basa en la necesidad de buscar formas para desmilitarizar la vida política del país y de forzar al sistema político existente, formalmente democrático pero en realidad excluyente, à la apertura y a la incorporación de fuerzas políticas a la izquierda del PDC. Así, se abre la posibilidad de que una democracia contrainsurgente se transforme gradual y lentamente en una democracia política real. Esta posición ha sido sin duda el dilema más importante a que se enfrentó el FMLN entre 1987 y 1989.

Para participar en las elecciones, se forma una nueva alianza a principios de noviembre de 1987 , denominada Convergencia Democrática, ${ }^{24}$ misma que durante 1988 decide participar en las elecciones presidenciales de 1989. Este hecho vuelve a confirmar la tendencia de que es posible abrir el régimen político, aun en el contexto de la guerra civil. El FMLN se encontró en el dilema de respaldar este esfuerzo o continuar la guerra. De hecho, fue un acto de autonomía política del MNR y MPSC (recuperando su original ideología), que orilló al FMLN a continuar la búsqueda del diálogo con el gobierno en forma independiente de los acontecimientos internos en el país.

En el nivel político-ideológico, es en el FMLN donde se han dado los más bruscos virajes. Del "Programa del Gobierno Democrático-Revolucionario", enunciado el 23 de febrero de 1980 por la entonces Coordinadora Revolu-

\footnotetext{
24 Véase "Los partidos", 1980, p. 346.
} 
cionaria de Masas (CRM) y avalado por el FDR en su creación ${ }^{25}$ (donde se enfatizan básicamente los temas relativos a un programa de gobierno que resalta la "democracia social", y donde participarían solamente los miembros del FDR y las organizaciones sociales que lo apoyan), se pasa a un "gobierno provisional de amplia participación", el 31 de enero de 1984, que menciona implícitamente la posibilidad de participación de otros sectores (o fórmulas conocidas como "compartir el poder"), haciendo alusión a la posibilidad de cogobierno con el PDC. El tercer viraje significativo se da la víspera de las elecciones presidenciales de 1989 , cuando se reconocen, por primera vez en ocho años de guerra civil, las estructuras legales $\mathrm{e}$ institucionales existentes y construidas por la oligarquía y el PDC, mencionando que se necesita un cambio en la fecha de las elecciones y que el FMLN acepta la propuesta de gobierno de la Convergencia Democrática:

El FMLN, haciendo últimos esfuerzos para detener el estallido social dándole a las elecciones un propósito superior para que contribuyan a una paz duradera, hace la siguiente propuesta política: postergar las elecciones del 19 de marzo y realizarlas en un plazo aproximado de 6 meses. [...]

Las condiciones en las que se realizan las actuales elecciones tas vuelven ilegitimas. Por ello el FMLN las ha rechazado y en tanto no se modifique esta situación, el FMLN mantendrá esa posición acompañando al pueblo en el rechazo a las actuales elecciones. El pro-

25 "Primera declaración", 1980, p. 346. ceso electoral actual agma la guerra [...] Nuestra propuesta contribuye a la paz. ${ }^{26}$

Estos cambios en la percepción del FMLN sobre la institucionalidad política existente hablan de virajes muy profundos de estrategia política. De una concepción donde se da un predominio de las concepciones de "democracia social" y se encuentran al margen las consideraciones de "démocracia política", se pasa a la ecuación inversa: la búsqueda de participación en el sistema político existente, reconociendo la legalidad de la Constitución de 1983 , y subordinando la posibilidad de "democracia social" a la urgencia de "democracia política". El hecho que explica este viraje fue la no resolución por la vía militar de la guerra, el aislamiento de sectores de población que incluso han cambiado radicalmente sus simpatías políticas en favor de la derecha y la ultraderecha (como lo demuestran las elecciones, donde, desde los comicios de 1988, para elegir la Asamblea Legislativa de 1988 logra la mayoría sobre el PDC), la nueva situación mundial (donde es muy importante la crisis del sandinismo en Nicaragua, el nuevo aislamiento cubano y el desmantelamiento de la Unión Soviética) y la consolidación del proceso de paz. En el FMLN se habla incluso de una nueva filosofia política de "distensión", y se reconoce que, para pasar a un periodo de re-

26 "Propuesta del FMLN para convertir las elecciones en una contribución a la paz, 23 de enero de 1989", en Benítez, Paz, 1989. Véase también Acevedo, "Propuesta", 1989. 
construcción del país, éste sólo es po. sible con la participación de todos los sectores económicos, sociales y políticos. Al mismo tiempo hay una revaloración de la acción parlamentaria y de la democracia liberal. ${ }^{27}$

\section{CONCLUSIONES}

Para analizar el debate existente sobre la democracia en El Salvador, recurrimos al análisis histórico, sin el cual, desde nuestra optica, no puede entenderse el momento actual. Por ello, el tema de la democracia es hoy un eje crucial por el que pasan las luchas políticas y sociales en E1 Salva. dor. La participación del FMLN en la vida política es un elemento sine qua non para poder confirmar que la construcción de la democracia en El Salvador hace realmente posible la presencia de todos los sectores. Hasta que no concluya el proceso de transición estipulado en los Acuerdos de Paz de Chapultepec, firmados el 16 de enero de 1992 (periodo de "paz armada",

27 Véanse los ensayos de Eduardo Sancho (miembro de la Comandancia General del FMLN), El Salvador, 1991; Meléndez, Cambios, 1990. Rafael Guidos Béjar en el ensayo "Tiempo", 1992 , señala que los cambios ideológicos en la izquierda salvadoreña han sido radicales, particularmente en el FMLN (lo menciona incluso como una "crisis de identidad"), debido a que durante el proceso de negociaciones, al darle prioridad a la política, se desvanece el binomio guerra-revolución, ahora cambiando el discurso político, transformándose la lucha del FMLN en el periodo de posguerra en una "revolución democrática". Por su parte, Terry Lynn Karl "Negotiated", 1992, señala que el proceso de negociación lo que en realidad negoció fue el "proyecto revolucionario". que va del 1 de febrero al 31 de octubre de 1992), ${ }^{28}$ no se puede hablar de éxito en la pacificación del país y su acompañante decisoria: la democratización real de la vida política. En un nivel más amplio, incluso en el proceso de negociaciones y paz, se presenta una fusión de las dos concepciones de la democracia (la social y la política) aceptada en ambos polos del espectro político (ARENA y FMIN), residiendo el dilema en los recursos que apuntalan la democracia, desde medios económicos hasta humanos y culturales. También, es preciso para la consolidación democrática que el tratado de paz se aplique en su letra y espíritu en forma amplia para que las cuestiones pendientes -como la reestructuración de las fuerzas armadas y el desmantelamiento de los cuerpos de seguridad-y el respeto a los derechos humanos puedan transformar la vida política. En un segundo nivel, como un problema de más largo plazo, se encuentra la superación de la pobreza extrema.

Entre las principales limitantes para la consolidación de una verdadera democracia se tiene la situación en que se encuentra el país en el momento de la firma de la paz, comparado con las condiciones de preguerra. Estimaciones globales de los daños de la guerra entre 1980 y 1989 (incluyendo aquellos causados por el terremoto de 1980) suman 3150 millones de dólares. ${ }^{29}$ A ello hay que agre-

28 "Acuerdo de Paz", 1992.

29 Cuadro titulado "El Salvador: estimación de pérdidas causadas por la guerra y el terremoto, 1980-1989, en Córdova, "El Salvador", 1992, p. 5. 
gar la transformación en economía de guerra y las dificultades de su reconversión; la fuga de capitales, observada principalmente durante los primeros años de la guerra; la dependencia casi total de los fondos económicos del gobierno federal de Estados Unidos, que sostuvieron la economía y el esfuerzo militar y por los cuales pudo evitarse el triunfo del FMLN, mismos que se estiman en 6000 millones de dólares (incluye esta cifra 4500 millones en ayuda económica y militar, 850 en créditos del gobierno federal de Estados Unidos, y 500 millones en gastos de la CIA.). ${ }^{30}$ Parte importante de la economía se sostiene con los productos agrícolas de exportación (tanto los tradicionales como los no tradicionales), mismos que han disminuido su valor en casi $50 \%$ en el mercado mundial en la última década. A lo anterior se añaden los cambios en la demografia del país: los casi 900000 salvadoreños que viven en Estados Unidos, los campesinos reubicados en la periferia de las ciudades, los desempleados y subempleados en la periferia de las ciudades, los desempleados y subempleados (que superan el $50 \%$ ), los muertos de la guerra (calculados en más de 70000 ), etcétera. Lo anterior muestra un panorama muy negativo que afecta el futuro de la consolidación del proceso de paz en lo inmediato y de la democracia en el largo plazo.

A nivel político, en la década de los noventa, El Salvador es un país con numerosas fuerzas políticas, las

30 Schwarz, American, 1991, p. 3 (este documento fue preparado para la Secretaría de la Defensa de Estados Unidos). cuales abarcan el conjunto de un espectro que va desde la extrema derecha (ARENA) hasta la extrema izquierda (FMLN). ${ }^{31}$ En el nivel intermedio, hay fuerzas políticas "moderadas" más abiertas a posibilidades de negociaciones amplias. En este colchón que amortigua el conflicto de los "extremos" se ubican el PDC (centro-derecha) y la Convergencia Democrática (centro-izquierda). Hoy por hoy, hay un problema central en El Salvador: las simpatías políticas se encuentran polarizadas (ARENA-FMLN) como una herencia directa de la guerra civil. Otro factor que afecta las posibilidades de democracia en el corto plazo es que ARENA y el PDC fueron los favorecidos durante los once años de guerra, pues el régimen político existente fue construido por ellos y para ellos, por lo cual no perciben la necesidad real de transformar sus concepciones políticas: en este aspecto, para ARENA la política debe seguir siendo militarizada; en cambio sí se observa flexibilidad en el campo de la izquierda, donde los virajes ideológicos han sido muy profundos. En otras palabras, no se acepta el resultado de la guerra que dio pie a la firma de la paz (el empate estratégico) como elemento para cam. biar la concepción de la convivencia política que exigen las nuevas circunstancias.

Otro factor que hay que tomar en cuenta es que en el seno de la sociedad civil hay sujetos sociales y políticos muy relevantes que han participado activamente en las acciones políticas (muchos de ellos dieron el mismo vi-

31 Esto ha sido estudiado en detalle en Córdova, "Partidos", 1992. 
raje ideológico observado en el FMLN, de la lucha por la revolución se pasa a luchar por la democracia). La guerra impidió su participación abierta y en numerosas ocasiones su represión fue la norma imperante. Estamos refiriéndonos a la Iglesia católica (tanto la regular como las congregaciones, siendo la más importante la jesuita, que entre 1984 y 1989 fueron mediadoras entre el FMLN y el gobierno) y a numerosos movimientos sociales, sindicales, etcétera, pues, dada la posibilidad de participar abiertamente en un futuro régimen político democrático, la vida política no podrá restringirse sólo a la competencia entre los partidos políticos, volviendo la democracia, de esta manera, a interrelacionar lo "político" con lo "social".

La legalidad político-constitucional existente vive su prueba de fuego con la aplicación de los acuerdos de paz. El futuro de la democracia se articula con el cumplimiento de sus disposiciones y éste demostrará si tal legalidad se puede transformar en legitimidad posibilitando así la construcción de una nueva hegemonía ( $y$ de un nuevo Estado), o si, por el contrario, seguirá siendo una legalidad y una constitucionalidad democrática muy frágil, como sucede en algunos países de América Latina, donde no se ha estabilizado la democracia. En El Salvador se da un contraste institucional y legal: la norma vigente es la convivencia de las disposiciones de los tiempos de la guerra y de la institucionalidad restringida con las disposiciones de los acuerdos de paz (por ejemplo, el poder paralelo que significan la Comisión Nacional Para la Consolidación de la Paz -COPAz-, vigente incluso antes de la firma del acuerdo completo de paz, y de la ONUSAL), ante la nueva presencia abierta y legal del FML.N. Estos elementos lógicamente no fueron contemplados en la Constitución de 1983 que, por el contexto de guerra en que fue redactada, es excluyente, prooligárquica y favorable al militarismo.

Esta nueva condición que vive El Salvador presenta un cuadro de superación definitiva de la guerra civil, pues el logro más importante de los acuerdos de paz, el cese del fuego, es un logro prácticamente irreversible, y una gradual conversión de las estructuras políticas hacia la democratización del régimen; sigue siendo uno de los riesgos de la transición la posibilidad de la reaparición de concepciones militaristas, tanto en ARENA y las fuerzas armadas, como en elementos no satisfechos del FMLN que pueden considerar un retroceso los Acuerdos de Paz. Otro factor es la resistencia de la oligarquía al cumplimiento de los acuerdos de paz, sobre todo en las disposiciones relativas al reparto agrario y otros compromisos que aluden a las graves desigualdades sociales, pues son focos de tensión recurrentes a lo largo de la historia de El Salvador.

\section{Cronograma De Cumplimiento de los acuerdos de Paz EN El Salvador}

COpaz. Es la Comisión Nacional para la Consolidación de la Paz que verificará los acuerdos y está integrada por dos representantes del FMLN, dos del gobierno (un representante del Ejército y uno de la Administración) 
y un representante de cada partido político o coalición de éstos con representación en la Asamblea Legislativa.

Enero 24, 1992. Presentación a la Asamblea Legislativa del anteproyecto de ley que la formaliza.

Febrero 1, 1992. COPAZ. Queda constituida formalmente.

\section{PARTICIPACIÓN POLÍTICA DEL FMLN}

Febrero 1, 1992. Fecha límite para adoptar medidas legislativas que garanticen ejercicio de derechos a ex combatientes y solución para la seguridad de dirigentes y participantes del FMLN.

Marzo 2, 1992. Liberación de detenidos políticos.

\section{Cese Del ENFRENTAMIENTO ARMADO}

Enero 25, 1992. Suministro por FMLN y gobierno a ONUSAL de información detallada sobre efectos y armas.

Febrero 1, 1992. Entra en vigor el cese al fuego.

Febrero 1-6, 1992. Primera etapa de separación de fuerzas.

Febrero 6 a marzo 2. Segunda etapa de separación de fuerzas.

Marzo 2, 1992. Concentración por el FMLN, en cada uno de los 15 lugares señalados, de armas, municiones, minas, explosivos y equipo militar del FMLN.

\section{REINCORPORACIÓN DEL. FMLN}

Mayo 1, 1992. Reincorporación de no menos del 20\%.
Mayo 31. Reincorporación de no menos del $40 \%$.

Julio 30, 1992. Reincorporación de no menos del $60 \%$.

Septiembre 28, 1992. Reincorporación de no menos del $80 \%$.

Octubre 31, 1992. Reincorporación deberá estar terminada.

Según los términos del acuerdo de paz, el gobierno se reducirá en $50.2 \%$ en un periodo de 24 meses contados a partir del primero de febrero próximo, sus efectivos pasarán de 63175 a poco más de 31000 en ese lapso.

Febrero 1, 1992. Fecha límite para que sea ratificada la reforma constitucional para el cambio de la estructura de la fuerza armada.

\section{Sistema EDUCATIVO}

Agosto 29, 1992. Determinación del sistema de admisión a la escuela militar por el consejo académico.

\section{DEPURACIÓN}

Enero 21, 1992. Se admite el acuerdo que formaliza la comisión ad hoc, que evaluará los términos del proceso de depuración

Mayo 16, 1992. Se establece la comisión.

\section{DESAPARICIÓN DE CUERPOS DE SEGURIDAD}

Marzo 2, 1992. Se suprimen la Policía Nacional Civil (PNC) y la Guardia Nacional como cuerpos de seguridad 
pública y sus efectivos se trasladarán al Ejército.

Junio 15, 1992. Fecha límite para la disolución de la Dirección Nacional de Inteligencia.

Marzo 2, 1992. Creación del organismo de inteligencia de Estado.

\section{DESMOVILIZACIÓN BaTALLONES DE INFANTERÍA DE REACCIÓN INMEDIATA}

Julio 17, 1992. Se desmoviliza el BIRI Ramón Belloso.

Agosto 31, 1992. Se desmoviliza el BIRI Atonal.

Septiembre 30, 1992. Se desmoviliza el BIRI Atlacatl.

Octubre 31, 1992. Se desmoviliza el BIRI Eugenio Bracamonte.

Noviembre 30, 1992. Se desmoviliza el BtrI José Manuel Arce.

Febrero 1, 1992. Se pone en práctica la suspensión.

Marzo de 1992. Difusión de la doctrina de la Fuerza Armada.

Policía Nacional CiviL

Febrero 6, 1992. COPAZ presenta terna para nombrar director general de la Academia Nacional de Seguridad Pública.

Febrero 21, 1992. Presentación a la Asamblea Legislativa del anteproyecto de ley orgánica para crear PNC (Policía Nacional Civil).

\section{Sistema JUDiCIAI.}

Marzo 2, 1992. Designación de procurador nacional para defensa de los derechos humanos.
Marzo 31, 1992. Presentación a la Asamblea Legislativa de anteproyecto para reformas a la ley.

\section{SISTEMA ELECTORAL}

Febrero 16, 1992. Designación de Tribunal Supremo Electoral.

\section{SISTEMA ECONÓMICO Y SOCIAL}

Febrero 18, 1992. FMLN presentará inventario de inmuebles o predios afectados dentro de zonas conflictivas.

Julio 14, 1992. Legalización de la tenencia de la tierra en zonas conflictivas.

Una cláusula del acuerdo establece que si alguna fecha hubiese quedado sin definir o algún inconveniente surgiera en algún momento, la ONUSAL (misión de verificación de la ONU), deberá definir la controversia.

Tomado de: Centroamérica Internacional, FLACsO, San José, núm. 8, 1992.

\section{BIBLIOGRAFIA}

-Acevedo, Carlos, "La propuesta de paz más viable del FMLN", en Benítez Manaut, Paz, 1989.

-"Acuerdo de Paz de Chapultepec", Panorama Centroamericano, núm. 37 , IN. CEP, enero-febrero de 1992.

-Anderson, Thomas, Matanza. El Salvador's communist revolt of 1932, University of Nebaska Press, 1981.

-Baloyra, Enrique, El Salvador en tran. síción, UCA Editores, San Salvador, 1987.

-Benítez Manaut, Raúl, La paz en Centroamérica: expediente de Documentos Fundamentales (1979-1989), Centro de Investigaciones Interdisciplinarias en $\mathrm{Hu}$ - 
manidades/Universidad Nacional Autónoma de México, México, 1989.

La teoria military la guerra civil en El Salvador, UCA Editores, San Salvador, 1989.

ㄴ. , "El Salvador: un equilibrio imperfecto entre los votos y las botas", Secuencia, núm. 17, mayo-agosto de 1990, pp. 71-92.

-Bermúdez, Lilia, Guerra de baja intensidad. Reagan contra Centroamérica, Siglo XXI Editores, México, 1987.

-Cabarrús, Carlos, Génesis de una revolución. Analisis del sungimiento y desarrollo de la organización campesina en El Salvador, La Casa Chata, México, 1983.

-Cáceres, Jorge, Rafael Guidos Béjar y Rafael Menjívar, El Salvador: una bistoria sin lecciones, flacso, San José de Costa Rica, 1988.

-Castro Morán, Mariano, Función politica del ejército salvadoreño en el presente siglo, UCA Editores, San Salvador, 1984.

-Celarié, Adela, "Surgimiento y desarrollo de las organizaciones populares en El Salvador, 1970-1980", tesis de maestría en flacso, México, 1983.

-Colindres, Eduardo, Fundamentos económicos de la burguesía salvadoreña, UCA Editores, San Salvador, 1977.

-2a. Constitución Política de El Salvador, Diario Oficial, 16 de diciembre de 1983.

Córdova, Ricardo, "Periodización del proceso de crisis (1979-1988)", en Edgar Jiménez y otros, El Salvador: guerra, política y paz (1979-1988)", CINAS, San Salvador, 1988.

"Partidos y elecciones en El Salvador (1982-1989)", Revista de Ciencias Sociales, núms. 54-55, Universidad de Costa Rica, diciembre de 1991-marzo de 1992.

, "El Salvador después de la

guerra: el costo de la esperanza", Centroamérica Internacional, FLACSO, núm. 8, San José, 1992.

-Gordon, Sara, Crisis política y guerra en El Salvador, Siglo XXI Editores, México 1989.
-Guidos Béjar, Rafael, El ascenso del militarismo en El Salvador, UCA Editores, San Salvador, 1980.

, "El tiempo del adiós", Polémica, flAcso, enero-abril de 1992.

-Herman, Edward y Frank Brodhead, Demonstration elections, U.S. staged elections in the Dominican Republic, Vietnam and El Salvador, Stohend Press, Boston, 1984.

-Jiménez, Eddy, La guerra no fue de fútbol, Casa de las Américas, La Habana, 1974.

-Jiménez, Edgar y otros, El Salvador: guerra, política y paz (1979-1988), CINAS, San Salvador, 1988.

-Karl, Terry Lynn, "El Salvador's negotiated revolution", Foreign Affairs, primavera 1992.

-"Los partidos políticos MNR, MPSC y PSD han dado pie a un proceso de convergencia democrática", Estudios Centroamericanos, núms. 469-470, UCA, San Salvador, noviembre-diciembre de 1987 , pp. 935 938.

-Meléndez, Jorge, Los cambios del mundo actual y el papel del movimiento revolucionario, Editorial Sistema Venceremos, 1990.

-Menjívar, Rafael, Formación y lucba del proletariado industrial salvadoreño, UCA Editores, San Salvador, 1982.

-"Primera declaración del Frente Democrático Revolucionario", San Salvador, 18 de abril de 1980 , Estudios Centroamericanos, núms. $377-380$, marzo-abril de 1980 , p. 346.

-Sancho, Eduardo, El Salvador frente a los desafíos del siglo XXI, FMLN, s. I., 1991.

-Schwarz, Benjamín, American Coun terinsurgency Doctrine and El Salvador, Rand Corporation, Santa Mónica, 1991.

-Waghelstein, John, "El Salvador: more Venezuela than Vietnam", Eagle, 1984.

-Waghelstein, John y Alvin Bernstein, "How to win in El Salvador", Policy Re. view, núm. 27, mayo de 1985. 